\title{
Electrostatic hierarchical co-assembly in aqueous solutions of two oppositely charged double hydrophilic diblock copolymers
}

\author{
Ilja K. Voets ${ }^{\mathrm{a}, \mathrm{b}, *}$, Arie de Keizer ${ }^{\mathrm{a}}$, Frans A.M. Leermakers ${ }^{\mathrm{a}}$, Antoine Debuigne ${ }^{\mathrm{c}}$, Robert Jérôme ${ }^{\mathrm{c}}$, \\ Christophe Detrembleur ${ }^{c}$, Martien A. Cohen Stuart ${ }^{\mathrm{a}}$ \\ a Laboratory of Physical Chemistry and Colloid Science, Wageningen University, Dreijenplein 6, 6703 HB Wageningen, The Netherlands \\ ${ }^{\mathrm{b}}$ Adolphe Merkle Institute, University of Fribourg, Route de l'ancienne Papeterie, P.O. Box 209, CH-1723 Marly 1, Switzerland \\ ${ }^{\mathrm{c}}$ Center for Education and Research on Macromolecules, University of Liège, Sart-Tilman B6, 4000 Liege, Belgium
}

\section{Introduction}

Electrostatic interaction between two oppositely charged molecules in aqueous solution leads to a macroscopic associative phase separation, known as complex coacervation [1], provided certain requirements such as proximity to charge neutrality, are met. Naturally, the tendency to phase separate is tuneable with parameters influencing the electrostatic interaction between the two (macro)molecules, such as ionic strength, mixing fraction, and $\mathrm{pH}$ in case of weak acids and/or bases. Moreover, the associative phase separation can be restricted to the colloidal domain by attaching a solvophilic group to one or both of the molecules, resulting in mixed aggregates, such as

\footnotetext{
* Corresponding author. Address: Adolphe Merkle Institute, University of Fribourg, Route de l'ancienne Papeterie, P.O. Box 209, CH-1723 Marly 1, Switzerland. Tel./fax: +41 (0)263009624.

E-mail address: ilja.voets@unifr.ch (I.K. Voets).
}

vesicles [2,3] or micelles [2-13]. As complex coacervation is the governing principle in the formation of this type of colloids, we employ the term complex coacervate core micelles (C3Ms) [9-12]. Other equivalent terms in use are polyion complex micelles [2-5], block ionomer complexes [6,7], or interpolyelectrolyte complexes (IPEC) [8]. C3Ms can be formed from virtually any combination of oppositely charged species, provided at least one of the species carries one or several solvophilic units that remain soluble upon complexation. By far the most studied are combinations including a diblock copolymer to stabilise the complex, while combinations with random [14] and graft [15] copolymers are relatively little reported on. Recent examples include C3Ms consisting of a copolymer and DNA [15,16], RNA [17], enzymes [5], homopolymer [10], dendrimer [3], drug [3], surfactant [14], metal ion [18,19], or coordination polymer [20]. Their potential as novel drug carrier systems, encapsulating for example DNA, RNA, enzymes, and drugs has widely been investigated [21-23]. 
Recently, we have reported on an entirely different application of C3Ms: we have found that these systems are well suited for the preparation of responsive compartmentalized polymeric micelles. We have shown that, by incorporation of two solvophilic entities with a tendency to avoid each other, it is possible to increase the level of structural hierarchy from a simple radial segregation into two domains, generally termed core-shell, into a coreshell assembly whereof the shell is additionally segregated laterally into two distinct domains. The simplest manner to obtain such a structure, for which the term 'Janus-micelle' is employed, is by mixing two diblock copolymers, each containing a charged or chargeable block, and a solvophilic (in this study hydrophilic, as all experiments are performed in aqueous solution) neutral block. Thus, electrostatic interaction is employed to force the two diblock copolymers to form one mixed aggregate, leaving the immiscible but hydrophilic neutral blocks no other choice than to avoid each other within the shell of the aggregate. Clearly, the force balance is delicate: strongly segregating neutral blocks cannot be employed, as they might lead to dissociation of the micelles, while on the other hand too compatible hydrophilic blocks will result in a mixed corona. This concept has been explored in a series of recent papers $[11,12,24-26]$ where we observed that a pair of relatively miscible hydrophilic blocks yielded spherical C3Ms with a mixed shell and a pair of relatively immiscible hydrophilic blocks yielded ellipsoidal micelles with a laterally segregated corona (Janus-micelles). A combination of poly(2-(N,N-dimethylamino)ethyl methacrylate)-blockpoly(glyceryl methacrylate), PDMAEMA $45-b$-PGMA ${ }_{90}$ and poly(acrylic acid)-block-poly(acrylamide), $\quad \mathrm{PAA}_{42}-b-$ $\mathrm{PAAm}_{417}$ resulted in spherical micelles with a mixed corona [11], while the Janus-type segregation was achieved in aqueous mixtures of poly ( $\mathrm{N}$-methyl-2-vinyl pyridinium iodide)-block-poly(ethylene oxide), $\mathrm{P}_{2} \mathrm{MVP}_{42}-b-\mathrm{PEO}_{446}$ and poly(acrylic acid)-block-poly(acrylamide), $\quad \mathrm{PAA}_{42}-b$ PAAm $_{417}[12,24,25]$. Within the corona of these micelles, the relatively immiscible PAAm and PEO blocks were approximately of equal size and abundance.

In the present contribution, we study the formation and structure of C3Ms of another pair of double hydrophilic block copolymers with the relatively immiscible blocks $\mathrm{PVOH}$ and PEO. As discussed above, we previously investigated a symmetric case; that is, roughly equal size and abundance of the corona forming blocks. Now, we shift our attention to a strongly asymmetric case: the $\mathrm{PVOH}$ chains constitute less than $14 \%$ of the monomers in the micellar corona, while the PVOH/PEO block length ratio $\left(N_{\mathrm{PVOH}} / N_{\mathrm{PEO}}\right)$ is varied between 0.4 and 0.9 . We will show that such conditions can still lead to a segregation of polymer chains within the micellar corona, while the overall micellar shape remains spherical. We propose to relate the structural differences between the C3Ms with the incompatible polymer pairs $\mathrm{PVOH} / \mathrm{PEO}$, as studied in the present contribution, and PAAm/PEO, as studied previously, to the difference in type of coronal segregation: patchwise segregation versus Janus-type segregation. Finally, we present some preliminary results of self-consistent field (SCF) calculations on brushes consisting of two chemically distinct polymers, with characteristics mimick- ing our experimental system consisting of PVOH and PEO chains. They were found to be in good agreement with our interpretation of the experimental results: a patchwise segregation of coronal blocks was found for both longer and shorter PEO than PVOH blocks for a wide range of potential PEO-PVOH and PVOH-water Flory-Huggins interaction parameters (that is, parameters characterising the immiscibility of the polymer pair and the $\mathrm{PVOH}$ solvent quality).

\section{Materials and methods}

\subsection{Materials}

Three different samples of poly( $N$-methyl-2-vinyl pyridinium iodide)-block-poly(ethylene oxide), $\mathrm{P}^{-\mathrm{MVP}_{38^{-}}}$ $b-\mathrm{PEO}_{211}, \mathrm{P} 2 \mathrm{MVP}_{42}-b-\mathrm{PEO}_{446}$, and $\mathrm{P}_{2} \mathrm{MVP}_{71}-b-\mathrm{PEO}_{454}$ have been synthesised by sequential anionic polymerisation (polydispersity index, PDI < 1.05) by H. Schmalz (Bayreuth University) [12,27], followed by quaternisation with methyl iodide. [The subscripts correspond to the degree of polymerisation.] The average degree of quaternisation has been determined by elemental analysis and was found to be $89 \pm 2 \%$. 2,2'-Azo-bis-(4-methoxy-2,4-dimethyl valeronitrile) (V-70) (Wako) and cobalt (II) bis-acetylacetonate $(>98 \%$, Merck) were used as received. Vinyl acetate (VAc) and acrylonitrile (AN) (Aldrich) were dried over calcium hydride, degassed by several freeze-thawing cycles before being distilled under reduced pressure. All polymerisation experiments were performed by classical Schlenck techniques under nitrogen. Liquids were transferred with syringes and stainless steel capillaries.

\subsection{Synthesis of poly(acrylic acid)-block-poly(vinyl alcohol), $P A A_{305}-b-P V O H_{184}$ [28]}

\subsubsection{Synthesis of poly(vinyl acetate)-block- poly (acrylonitrile) ( $\left.P V A c_{184}-b-P A N_{305}\right)$}

$\mathrm{Co}(\mathrm{acac})_{2}\left(0.140 \mathrm{~g}, 5.44 \cdot 10^{-4} \mathrm{~mol}\right)$ and V-70 $(0.546 \mathrm{~g}$, $1.77 \cdot 10^{-3} \mathrm{~mol}$ ) were added into a $50 \mathrm{ml}$ flask and degassed by three vacuum-nitrogen cycles. Vinyl acetate $(15.0 \mathrm{ml}$, $0.162 \mathrm{~mol}$ ) was then added with a syringe under nitrogen. The purple mixture was stirred and heated at $30^{\circ} \mathrm{C}$ until the monomer conversion reached $50 \%(\sim 40 \mathrm{~h})$. A sample is withdrawn for SEC analysis in THF $\left(M_{\mathrm{n}}\right.$ (SEC, THF) = $15800 \mathrm{~g} \mathrm{~mol}^{-1} ; M_{\mathrm{w}} / M_{\mathrm{n}}=1.22$ ) which gives a molecular weight very close to the molecular weight determined by ${ }^{1} \mathrm{H}$ NMR $[29,30]$, before removal of the unreacted vinyl acetate under vacuum at room temperature. After dissolution of PVAc in a degassed anisole/toluene (9/1: v/v; $15 \mathrm{ml})$, mixture, distilled and degassed acrylonitrile $(10 \mathrm{ml}$, $0.151 \mathrm{~mol}$ ) was added. The reaction medium was stirred for $30 \mathrm{~min}$ at $30{ }^{\circ} \mathrm{C}(\sim 90 \%$ conversion). The crude mixture was then diluted by DMF and the copolymer was precipitated in a methanol/water (20/80) mixture. This purification step was repeated two times before SEC analysis $\left(M_{\mathrm{n}}\right.$ $(\mathrm{SEC}, \mathrm{DMF})=117,000 \mathrm{~g} \mathrm{~mol}^{-1} ; M_{\mathrm{w}} / M_{\mathrm{n}}=1.44$ compared to the macroinitiator eluted in the same conditions: $M_{\mathrm{n}}$ (SEC, DMF) $\left.=65,400 \mathrm{~g} \mathrm{~mol}^{-1} ; \quad M_{\mathrm{w}} / M_{\mathrm{n}}=1.14\right)$. The unreacted 
PVAc macroinitiator was then removed from the copolymer by Soxhlet extraction with methanol for $48 \mathrm{~h}$ and the pure PVAc- $b$-PAN copolymer was recovered $\left(M_{\mathrm{n}}\right.$ (SEC, $\left.\mathrm{DMF})=138,100 \mathrm{~g} \mathrm{~mol}^{-1} ; M_{\mathrm{w}} / M_{\mathrm{n}}=1.37\right) .{ }^{1} \mathrm{H}$ NMR analysis of the copolymer in DMSO allows the determination of the copolymer composition by integrating the signal characteristic of $-\mathrm{CH}_{2}-\mathrm{CH}(\mathrm{OAC})-$ of PVAc and $-\mathrm{CH}_{2}-$ $\mathrm{CH}(\mathrm{CN})-$ of PAN at 4.85 and $3.35 \mathrm{ppm}$, respectively $\left(\right.$ PVAc $_{184}-b-$ PAN $\left._{305}\right)$.

\subsubsection{Hydrolysis of PVAc- $b-P A N$ into $P V_{184}-b-P A A_{305}$}

PVAc- $b$-PAN $(0.5 \mathrm{~g}$ ) was added to a $100 \mathrm{ml}$ flask, followed by $10 \mathrm{ml}$ ethanol and $45 \mathrm{ml}$ of an aqueous $\mathrm{KOH}$ solution ( $2.0 \mathrm{~g} \mathrm{KOH}$ in $90 \mathrm{ml}$ of water). The mixture was stirred at $75^{\circ} \mathrm{C}$ for $24 \mathrm{~h}$. The insoluble polymer rapidly became red and then yellow when slowly solubilising in the reaction medium. After hydrolysis, the copolymer was precipitated three times in THF, solubilised in water, dialysed for $48 \mathrm{~h}$ against pure water through a 6000-8000 Spectrapore membrane, and finally lyophilised to give a white powder. ${ }^{1} \mathrm{H}$ NMR analysis of the copolymer in $\mathrm{D}_{2} \mathrm{O}$ confirmed the complete hydrolysis of both blocks as assessed by the disappearance of the signal characteristic of $-\mathrm{CH}_{2}-\mathrm{CH}(\mathrm{OAc})-$ of PVAc at $4.85 \mathrm{ppm}$ and the signal characteristic of $\mathrm{CH}_{2}-\mathrm{CH}(\mathrm{CN})-$ of PAN at $3.35 \mathrm{ppm}$, and the appearance of new signals characteristic of $-\mathrm{CH}_{2}-\mathrm{CH}(\mathrm{OH})-$ of $\mathrm{PVOH}$ at $4.05 \mathrm{ppm}$ and of $-\mathrm{CH}_{2}-\mathrm{CH}(\mathrm{COOH})-$ of PAA at $2.15 \mathrm{ppm}$.

The chemical structure of the diblock copolymers used in this study is depicted in Fig. 1.

\subsection{Sample preparation}

Aqueous solutions of the polymers were prepared by dissolution of known amounts of polymer into de-ionised water (Milli-Q) to which known amounts of $\mathrm{NaNO}_{3}$ were added, followed by a pH-adjustment using $\mathrm{NaOH}$ and $\mathrm{HNO}_{3}$. For 2D ${ }^{1} \mathrm{H}$ NOESY NMR experiments, $\mathrm{D}_{2} \mathrm{O}(>99 \%$ deuterium, Aldrich) was used instead of de-ionised water. Unless otherwise specified, all experiments were performed at $25.0 \pm 0.2{ }^{\circ} \mathrm{C}$ and $1 \mathrm{mM} \mathrm{NaNO}_{3}$. For the polymer solutions in $\mathrm{D}_{2} \mathrm{O}$, the measured apparent $\mathrm{pH}$ value, $\mathrm{pH}_{\mathrm{app}}$, has been corrected for isotope effects [31] using Eq. (1) wherein pI is the generalised equivalent of $\mathrm{pH}$ including all isotopes and $n$ is the atom fraction of deuterium in the solvent.

$\mathrm{p} I=\mathrm{pH}_{\mathrm{app}}+0.3314 n+0.0766 n^{2}$

Polymer solutions were filtered at least once over a $0.45 \mu \mathrm{m}$ Schleicher and Schuell filter prior to mixing. This is necessary as C3Ms have a tendency to adsorb to a wide variety of surfaces [9], so that solutions cannot be filtered after mixing. Table 1 gives an overview of the stock solutions.

We define the important experimental parameter mixing fraction, $f_{+}$, as the number of positively chargeable (2VP) and charged (2MVP) monomers divided by the total number of chargeable and charged monomers (2VP, 2MVP, and $\mathrm{AA}$ ).

$f_{+}=\frac{[+]}{[+]+[-]}$

\subsection{Light scattering}

Light scattering measurements have been performed on an ALV light scattering instrument equipped with an ALV5000 digital correlator and a Spectra Physics $20001 \mathrm{~W}$ argon ion (dynamic and static light scattering, DLS/SLS) laser or a $400 \mathrm{~mW}$ argon ion laser (light scattering-titrations, LS$\mathrm{T}$ ) operated at a wavelength, $\lambda$, of $514.5 \mathrm{~nm}$. A refractive index matching bath of filtered cis-decalin surrounded the cylindrical scattering cell, and the temperature was controlled at $21.5 \pm 0.3^{\circ} \mathrm{C}$ using a Haake F3-K thermostat (DLS/SLS) and at $25 \pm 0.2^{\circ} \mathrm{C}$ using a Haake F8-C35 thermostat (LS-T).

\subsubsection{Light scattering-titrations ( $L S-T)$}

LS-Ts were performed at a fixed scattering angle, $\theta$, of $90^{\circ}$. A Schott-Geräte computer-controlled titration setup controlled sequential addition of titrant and cell stirring. The $\mathrm{pH}$ was measured with a combined $\mathrm{Ag} / \mathrm{AgCl}$ glass electrode. The recorded $\mathrm{mV}$ values were converted into $\mathrm{pH}$ values after calibration of the electrode with five buffers of known $\mathrm{pH}(3 \leqslant \mathrm{pH} \leqslant 7)$. After every dosage, $\mathrm{pH}, 90^{\circ}$ light scattering intensity, $I_{90^{\circ}}$, and the second-order correlation function, $G_{2}(t)$ were recorded, the latter two 5 times during a period of $25 \mathrm{~s}$. Averaged values of the intensity, $i_{\text {rel }}^{\sigma}$ (see

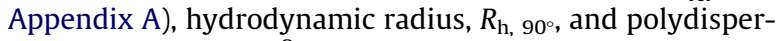
sity index, PDI ( $\mu_{2} / \Gamma^{2}$, method of cumulants) are reported as a function of $f_{+}$. For the mole fraction titrations, we introduce the reduced excess relative intensity, $i_{\text {rel }}^{\sigma}$, to present $I_{90^{\circ}}$ as a function of $f_{+}$in a manner independent of the experimental design, i.e., independent of the light scattering instrument, volume changes, concentration of titrant et cetera. See Appendix A for more details.

\subsubsection{Dynamic light scattering (DLS)}

A minimum of five second-order correlation functions $G_{2}(t)$ were recorded at 24 angles, $\theta$, from $30^{\circ}$ to $145^{\circ}$ in

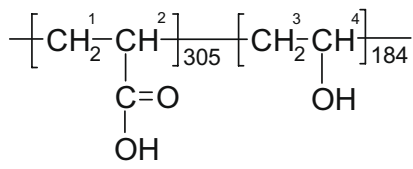

Fig. 1. Chemical structure of the diblock copolymers used in this study. Left: poly( $N$-methyl-2-vinyl pyridinium iodide)-block-poly(ethylene oxide), P2MVPX- $b$-PEOy $\left(x_{1}=38, y_{1}=211, M_{\mathrm{w}}=18088 \mathrm{~g} \mathrm{~mol}^{-1} ; x_{2}=42, y_{2}=446, M_{\mathrm{w}}=29366 \mathrm{~g} \mathrm{~mol}^{-1} ; x_{3}=71, y_{3}=454, M_{\mathrm{w}}=36428 \mathrm{~g} \mathrm{~mol}^{-1}\right)$. Note that $x$ denotes the sum of the number of quaternised and non-quaternised monomers. Right: Poly(acrylic acid)-block-poly(vinyl alcohol), $\mathrm{PAA}_{305}-b$ - $\mathrm{PVOH}_{184}$ $\left(M_{\mathrm{w}}=30085 \mathrm{~g} \mathrm{~mol}^{-1}\right)$. The numbers beside the brackets denote the degree of polymerisation. The numbers $1-5$ correspond to the chemical shifts listed in Table 4. 
Table 1

Overview of all polymer stock solutions used in this study.

\begin{tabular}{|c|c|c|c|c|}
\hline \multirow[t]{2}{*}{ Solution } & \multicolumn{2}{|l|}{$C_{\mathrm{p}}$} & \multirow[t]{2}{*}{ Solvent } & \multirow[t]{2}{*}{$\mathrm{p} I$} \\
\hline & $\mathrm{g} \mathrm{l}^{-1}$ & $\mathrm{~mol} \mathrm{l}^{-1}$ & & \\
\hline $\mathrm{P}_{2 M V P} \mathrm{MV}_{38}-b-\mathrm{PEO}_{211}{ }^{\mathrm{a}}$ & 10.42 & $5.58 \cdot 10^{-4}$ & $\mathrm{H}_{2} \mathrm{O}$ & 7.81 \\
\hline $\mathrm{PAA}_{305}-b-\mathrm{PVOH}_{184}{ }^{\mathrm{a}}$ & 0.52 & $1.72 \cdot 10^{-5}$ & $\mathrm{H}_{2} \mathrm{O}$ & 7.70 \\
\hline $\mathrm{P}_{2} \mathrm{MVP}_{38}-b-\mathrm{PEO}_{211}{ }^{\mathrm{b}}$ & 11.02 & $6.09 \cdot 10^{-4}$ & $\mathrm{D}_{2} \mathrm{O}$ & 7.73 \\
\hline $\mathrm{P}_{2} \mathrm{MVP}_{42}-b-\mathrm{PEO}_{446}{ }^{\mathrm{b}}$ & 11.05 & $3.76 \cdot 10^{-4}$ & $\mathrm{D}_{2} \mathrm{O}$ & 7.75 \\
\hline $\mathrm{P}^{2} \mathrm{MVP}_{71}-b-\mathrm{PEO}_{454}{ }^{\mathrm{b}}$ & 11.09 & $3.04 \cdot 10^{-4}$ & $\mathrm{D}_{2} \mathrm{O}$ & 7.69 \\
\hline $\mathrm{PAA}_{305}-b-\mathrm{PVOH}_{184^{\mathrm{b}}}$ & 4.10 & $1.36 \cdot 10^{-4}$ & $\mathrm{D}_{2} \mathrm{O}$ & 7.73 \\
\hline
\end{tabular}

a Stock solutions used in the mole fraction titration. For P2MVP $38-b$ $\mathrm{PEO}_{211}$ and $\mathrm{PAA}_{305}-b-\mathrm{PVOH}_{184}$. $C_{\mathrm{p}}$ corresponds to the concentration in the burette and in the titration cell respectively, prior to the light scatteringtitration.

b Stock solutions used to prepare samples for 2D ${ }^{1} \mathrm{H}$ NMR NOESY, DLS, and SLS measurements.

increments of $5^{\circ}$ to evaluate the angular dependence of the diffusion coefficient. The diffusion coefficient, extrapolated to zero angle, $D^{0}$, has been obtained from the slope in a plot of the average frequency, $\Gamma$ (obtained from a cumulant or CONTIN analysis of the data) versus $q^{2}$. Via the Stokes-Einstein equation, $D^{0}$ has been calculated into $R_{\mathrm{h}}{ }^{0}$ to be compared with the radius of gyration extrapolated to zero angle, $R_{\mathrm{g}}{ }^{0}$ obtained from static light scattering measurements. Moreover, the CONTIN routine has been used to analyse the DLS data in terms of size distributions.

\subsubsection{Static light scattering (SLS)}

The angular dependence of the excess Rayleigh ratio, $R(\theta, C)$ was recorded at 24 angles from $30^{\circ}$ to $145^{\circ}$ in increments of $5^{\circ}$, and has been analysed in terms of both the Zimm and Guinier approximation. Toluene was used as a reference. We refer to Appendix B for more details.

\section{5. ${ }^{1} \mathrm{H} N M R$}

Nuclear Overhauser Effect Spectroscopy (NOESY) is a two-dimensional NMR technique probing internuclear distances by means of the Nuclear Overhauser Effect. A more detailed introduction on the technique can be found in a previous publication [11]. ${ }^{1} \mathrm{H}$ NMR spectra of the micellar solutions were recorded at $298 \mathrm{~K}$ on a Bruker AMX-500 spectrometer, operating at $500 \mathrm{MHz}$, located at the Wageningen NMR Centre. For the 2D NOESY spectrum 976 experiments of 2048 data points were recorded, using standard Bruker software. The mixing time was $500 \mathrm{~ms}$.

\subsection{Size exclusion chromatography (SEC)}

SEC of polyvinyl acetate was carried out in THF (flow rate: $1 \mathrm{ml} \mathrm{min}^{-1}$ ) at $40{ }^{\circ} \mathrm{C}$ with a Waters 600 liquid chromatograph equipped with a 410 refractive index detector and styragel HR columns (four columns HP PL gel $5 \mu \mathrm{m}$ $10^{5}, 10^{4}, 10^{3}$, and $10^{2} \AA$ ). Polystyrene standards were used for calibration. The molar mass of PVAc determined by SEC in these conditions with PS calibration was in good agreement with that determined by ${ }^{1} \mathrm{H}$ NMR whenever the $\alpha$ end group of the initiator $\left(-\mathrm{OCH}_{3}\right.$ at $\left.\delta=3.13 \mathrm{ppm}\right)$ could be observed and compared to the $-\mathrm{CHOCOCH}_{3}$ proton at $\delta=4.8 \mathrm{ppm}$ of the monomer unit $[29,30]$. Size exclusion chromatography (SEC) of poly(vinyl acetate)-b-poly(acrylonitrile) was carried out in dimethylformamide containing

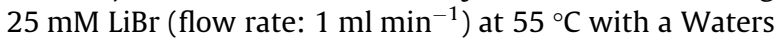
600 liquid chromatograph equipped with a 410 refractive index detector (four columns Waters styragel HR 1 (1005000), HR 3 (500-30,000), HR 4 (5000-500,000), HR 5 $(2000-4,000,000)(7.8 \times 300 \mathrm{~mm})$. Poly(styrene) standards were used for calibration.

\section{Results and discussion}

\subsection{Micelle formation}

Fig. 2 shows the apparent hydrodynamic radius at a scattering angle of $90^{\circ}, R_{\mathrm{h}, 90^{\circ}}$, the reduced excess relative intensity, $i_{\text {rel }}^{\sigma}$, and the polydispersity index, PDI as a function of the mixing fraction, $f_{+}$for a mole fraction light scattering-titration of an aqueous solution of $\mathrm{P}_{2} \mathrm{MVP}_{38}-b-$ $\mathrm{PEO}_{211}\left(C_{\mathrm{p}}=10.42 \mathrm{~g} \mathrm{l}^{-1}=5.58 \cdot 10^{-4} \mathrm{M}, \mathrm{pH} 7.81\right)$ to an aqueous solution of $\mathrm{PAA}_{305}-b-\mathrm{PVOH}_{184}\left(C_{\mathrm{p}}=0.52 \mathrm{~g} \mathrm{l}^{-1}=\right.$ $\left.1.72 \cdot 10^{-5} \mathrm{M}, \mathrm{pH} 7.70\right)$ at $1 \mathrm{mM} \mathrm{NaNO}_{3}$ and $25.0 \pm 0.1^{\circ} \mathrm{C}$. The picture is clearly reminiscent of previously reported light scattering-titrations on aqueous solutions of complex coacervate core micelles [10,25,32]. We can distinguish three regimes. The first regime, $0 \leqslant f_{+} \leqslant 0.25$, is characterised by high apparent values of $R_{\mathrm{h}, 90^{\circ}}$ and PDI, both decreasing with increasing $f_{+}$, and low values of $i_{\text {rel }}^{\sigma}$ increasing with increasing $f_{+}$. The second regime, $0.25 \leqslant f_{+} \leqslant 0.55$, shows a maximum in $i_{\text {rel }}^{\sigma}$ and minimum in PDI at $f_{+} \approx 0.4$ while $R_{\mathrm{h}, 90^{\circ}}$ is nearly constant at $17.8 \pm 0.4 \mathrm{~nm}$. In the third regime, $i_{\text {rel }}^{\sigma}$ seems fairly constant while $R_{\mathrm{h}, 90^{\circ}}$ and PDI appear to increase slightly. Note that the kinetics of complexation has been reported to be $f_{+}$dependent, so that full equilibrium may not have been established for all values of $f_{+}$[33]. Moreover, the $R_{\mathrm{h}, 90^{\circ}}$ values reported for this mole

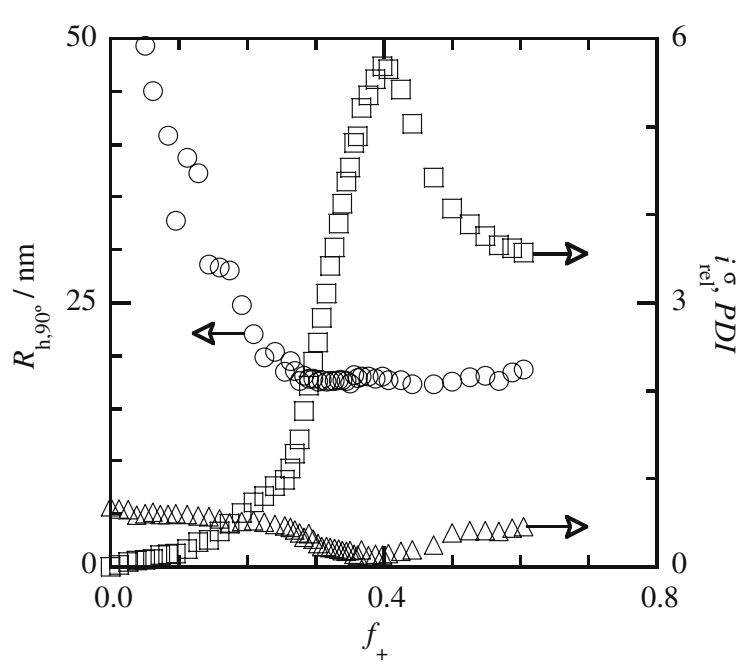

Fig. 2. $R_{\mathrm{h}, 90^{\circ}}$ (circles), $i_{\text {rel }}^{\sigma}$ (squares), and PDI (triangles) as a function of $f_{+}$ for a mole fraction light scattering-titration of an aqueous solution of

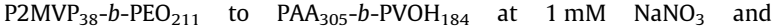
$T=25.0 \pm 0.1^{\circ} \mathrm{C}$. Arrows indicate corresponding axes. 
fraction titration are apparent values, i.e., they have not been extrapolated to zero concentration or angle.

Rather strikingly, $R_{\mathrm{h}, 90^{\circ}}$ and $i_{\text {rel }}^{\sigma}$ do not show the expected dependence on $f_{+}$, that is, symmetric around the preferred micellar composition, PMC, of $f_{+}=0.4$, as is commonly observed for C3Ms consisting of two annealed (co)polymers $[10,34]$. The present results are somewhat different, particularly in the third regime, i.e., for $f_{+} \geqslant 0.55$. For $0 \leqslant f_{+} \leqslant 0.25$, complexes between oppositely charged diblock copolymers are formed, evolving (most likely) from large, loose aggregates into better defined, smaller and denser structures, as indicated by the increase in $i_{\text {rel }}^{\sigma}$ and decrease in PDI and $R_{\mathrm{h}, 90^{\circ}}$ for increasing $f_{+}$. For $0.25 \leqslant f_{+} \leqslant 0.55$, these aggregates associate into C3Ms and consecutively partially dissociate into another type of soluble complexes, resulting in a maximum excess scattering and minimum PDI at $f_{+}=0.4$, the so-called preferred micellar composition. Note that the PMC is displaced from the expected $f_{+}=0.5$, which implies not all chargeable PAA groups are involved in the complexation.

Both the asymmetric dependence of $R_{\mathrm{h}, 90^{\circ}}$ and $i_{\text {rel }}^{\sigma}$ on $f_{+}$, and the displacement of the PMC from $f_{+}=0.5$ to $f_{+}=0.4$ can be related to the degree of quaternisation of $\mathrm{P}_{2} \mathrm{MVP}_{38}-b-\mathrm{PEO}_{211}$ and the large difference between $N_{\mathrm{PAA}}$ and $N_{\text {P2MVP. }}$ It is possible to roughly estimate the degree of quaternisation from the peak position in Fig. 2. At the PMC, charge neutrality is met, i.e., $f_{+} \alpha_{+}=f_{-} \alpha_{-}$. From the position of the PMC, $f_{+}=0.4$, and $\alpha_{-}=0.60$ (measured for $\mathrm{PAA}_{42}$ in $5 \mathrm{mM} \mathrm{NaNO}$ at the same pH [35], being 6.51, i.e., the $\mathrm{pH}$ decreases during the LS-T due to complexation as PAA units deprotonate and the solution $\mathrm{pH}$ is not buffered), we obtain $\alpha_{+}=0.91$, i.e., in excellent agreement with the value determined by elemental analysis (see experimental section). However, it is evident that the degree of PAA dissociation is not only determined by bulk $\mathrm{pH}$, but also by proximity to the cationic copolymer (a phenomenon that is generally referred to as charge regulation), i.e., one should actually determine $\alpha_{-}$from a protonation curve in the presence (not absence) of $\mathrm{P}_{2} \mathrm{MVP}_{38}-b-\mathrm{PEO}_{211}$. Furthermore, partial compensation of PAA by monovalent counterions instead of P2MVP segments could be an alternative explanation for the displacement of the PMC from the expected $f_{+}=0.5$. We would like to refer the interested reader to Appendix $\mathrm{C}$ for more details.

The complexes formed for $f_{+}>0.4$ are stabilised by excess positive charge, while those for $f_{+}<0.4$ are stabilised by excess negative charge. Typically, these soluble complexes dissociate into their molecular constituents at some point far away from charge neutrality, resulting in zero $i_{\text {rel }}^{\sigma}$ $[10,34]$. Indeed, this dissociation is observed for the soluble complexes stabilised by excess negative charge, but not for those stabilised by excess positive charge; those remain relatively stable for $f_{+} \geqslant 0.55$. We propose to attribute this difference to the molecular architecture of the diblock copolymers. Whereas $\mathrm{PAA}_{305}-b-\mathrm{PVOH}_{184}$ remains watersoluble in uncharged state (data not shown), P2VP-PEO forms micelles in aqueous solutions for $\mathrm{pH}>6.1$ [8]. Although the $\mathrm{P}_{2} \mathrm{MVP}_{38}-b-\mathrm{PEO}_{211}$ in this study is about $90 \%$ quaternised, the relatively hydrophobic backbone may enhance stability of the C3Ms and cationic complexes, as recently reported elsewhere [36].

In sharp contrast to traditional polymeric micelles consisting of amphiphilic polymers, C3Ms may be in thermodynamic equilibrium [1,11]. To test whether this also applies to the system under investigation, we have compared micellar sizes for C3Ms of $\mathrm{P}_{2} \mathrm{MVP}_{38}-b-\mathrm{PEO}_{211}$ and $\mathrm{PAA}_{305}-b-\mathrm{PVOH}_{184}$ at the preferred micellar composition prepared in a one-step fashion by simply mixing the polymer solutions and those obtained in the corresponding LST experiment, using the same stock solutions (Table 1 ). For the titration method, we find $R_{\mathrm{h}, 90^{\circ}}=18.3 \pm 0.1 \mathrm{~nm}\left(C_{\mathrm{p}}=\right.$ $1.87 \mathrm{~g} \mathrm{l}^{-1}, f_{+}=0.39$ ), while we find $R_{\mathrm{h}, 90^{\circ}}=18.1 \pm 0.3 \mathrm{~nm}$ $\left(C_{\mathrm{p}}=1.87 \mathrm{~g} \mathrm{l}^{-1}, f_{+}=0.40\right)$ for the one-step procedure. Moreover, for C3Ms of $\mathrm{P}_{2} \mathrm{MVP}_{38}-b-\mathrm{PEO}_{211}$ and $\mathrm{PAA}_{305}-b$ $\mathrm{PVOH}_{184}$ in $\mathrm{D}_{2} \mathrm{O}$ (Table 2), we find $R_{\mathrm{h}, 90^{\circ}}=18.7 \pm 0.2 \mathrm{~nm}$ $\left(C_{\mathrm{p}}=7.86 \mathrm{~g}^{-1}, f_{+}=0.40\right)$. Hence, we find no dependence of micellar size on preparation protocol, suggesting that indeed these C3Ms might be equilibrium structures. At the same time, the data suggest that neither concentration nor a change of solvent from $\mathrm{H}_{2} \mathrm{O}$ to $\mathrm{D}_{2} \mathrm{O}$, has considerable effect on micellar characteristics.

\subsection{Micellar structure}

Figs. 3 and 4 show the angular dependence of the frequency, $\Gamma$ (Fig. 3), and the excess Rayleigh ratio, $R(\theta, C)$ (Fig. 4) as a function of $q^{2}$. We observe a linear dependence of $\Gamma$ on $q^{2}$ (Fig. 3), which is a signature of a diffusive mode, and an upturn for small $q$ values in the static light scattering results (Fig. 4), indicative of an increase in average scattering mass; that is, the presence of a small fraction of larger aggregates. These results are corroborated by a CONTIN analysis which clearly reveals the presence of two distinctive modes for all three systems (Fig. 5). For the fast mode corresponding to single micelles we again find a linear dependence of $\Gamma$ on $q^{2}$ (Fig. 3b). Therefore, we have

Table 2

Light scattering results for the mixtures of polymer stock solutions in Table 1 . Data obtained for $T=21.5 \pm 0.3{ }^{\circ} \mathrm{C}$. Viscosity of $\mathrm{D}_{2} \mathrm{O}$ was calculated to be $1.2062 \pm 0.0095 C_{\mathrm{P}}$ at this temperature [56]. For all C3Ms, $d n / d c$ has been estimated at $\left.0.158 \mathrm{~cm}^{3} \mathrm{~g}^{-1} . \mathrm{Radii} / \mathrm{nm}^{0} D^{0} / 10^{-8} \mathrm{~cm}^{2} \mathrm{~s}^{-1}\right), M_{\mathrm{w}} / \mathrm{kg} \mathrm{mol}^{-1}$.

\begin{tabular}{|c|c|c|c|c|c|c|c|c|c|c|c|c|}
\hline Cationic polymer & $f_{+}$ & $D^{0}$ & $R_{\mathrm{h}}{ }^{0 \mathrm{c}}$ & $R_{\mathrm{h}}{ }^{0 \mathrm{~d}}$ & $M_{\mathrm{w}}^{\mathrm{a}}$ & $M_{\mathrm{w}}^{\mathrm{b}}$ & $P_{\text {agg }}{ }^{+}$a & $P_{\text {agg }}{ }^{-a}$ & $R_{\mathrm{g}}{ }^{0 \mathrm{a}}$ & $R_{\mathrm{g}}{ }^{0 \mathrm{~b}}$ & $R_{\mathrm{g}}^{0} / R_{\mathrm{h}}{ }^{0 \mathrm{a}}$ & $R_{\mathrm{g}}{ }^{0} / R_{\mathrm{h}}{ }^{0 \mathrm{~b}}$ \\
\hline $\mathrm{P}_{2 M V P} \mathrm{M}_{38}-b-\mathrm{PEO}_{211}$ & 0.40 & 9.9 & 14.2 & 18.3 & 800 & 794 & 41 & 8 & 26.1 & 24.5 & 1.43 & 1.34 \\
\hline $\mathrm{P}^{2 M V P} \mathrm{M}_{42}-b-\mathrm{PEO}_{446}$ & 0.39 & 8.0 & 17.4 & 22.4 & 706 & 701 & 23 & 5 & 26.2 & 24.6 & 1.17 & 1.10 \\
\hline $\mathrm{P}_{2 M V P} \mathrm{MV}_{71}-b-\mathrm{PEO}_{454}$ & 0.40 & 7.4 & 20.4 & 24.2 & 1436 & 1434 & 37 & 13 & 18.8 & 18.2 & 0.78 & 0.75 \\
\hline
\end{tabular}

a Obtained by the Zimm approximation.

b Obtained by the Guinier approximation.

c Obtained from a CONTIN analysis.

d Obtained from a cumulant analysis. 

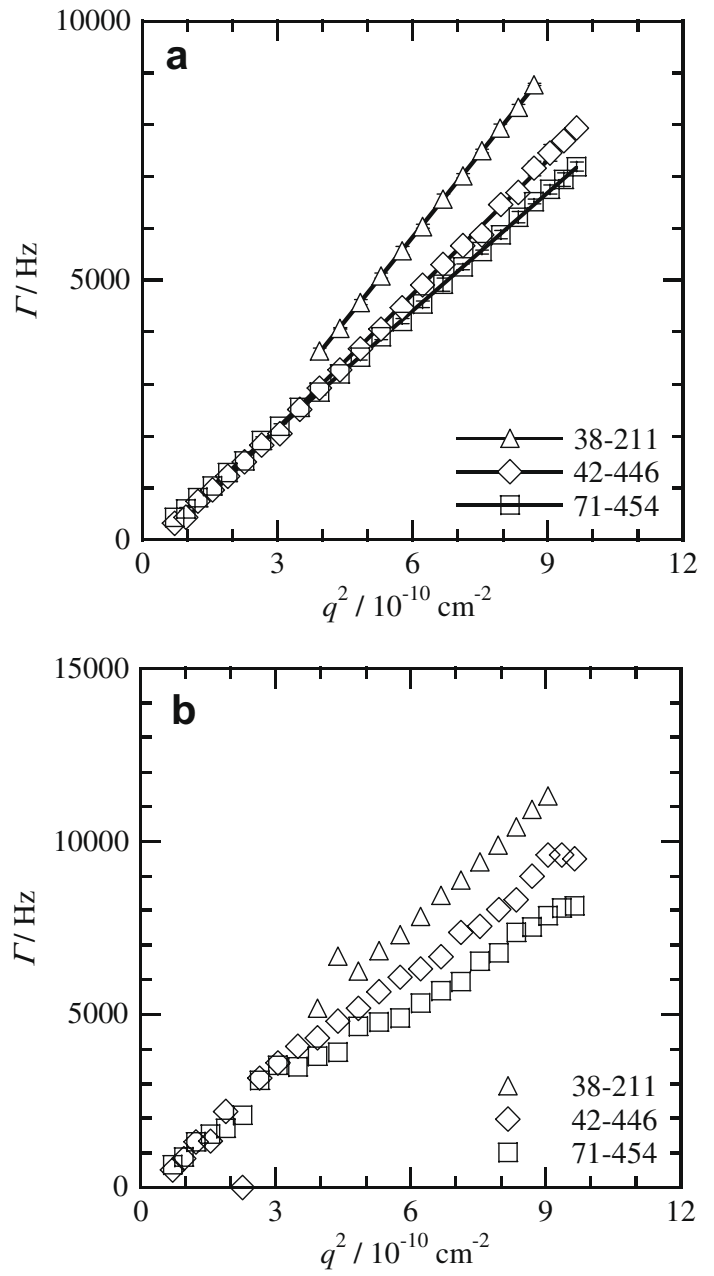

Fig. 3. (a) Cumulant and (b) CONTIN results. $\Gamma$ as a function of $q^{2}$ for mixtures of $\mathrm{PAA}_{305}-b-\mathrm{PVOH}_{184}$ and $\mathrm{P}_{2} \mathrm{MVP}_{38}-b-\mathrm{PEO}_{211}$ (triangles, $C_{\mathrm{p}}=7.86 \mathrm{~g} \mathrm{l}^{-1}, f_{+}=0.40$ ), $\mathrm{P}_{2} \mathrm{MVP}_{42}-b-\mathrm{PEO}_{446}$ (diamonds, $C_{\mathrm{p}}=8.48 \mathrm{~g} \mathrm{l}^{-1}$, $f_{+}=0.39$ ), and $\mathrm{P}^{2} \mathrm{MVP}_{71}-b-\mathrm{PEO}_{454}$ (squares, $C_{\mathrm{p}}=8.01 \mathrm{~g} \mathrm{l}^{-1}, f_{+}=0.40$ ) at $1 \mathrm{mM} \mathrm{NaNO}_{3}$ and $T=21.5 \pm 0.3^{\circ} \mathrm{C}$.

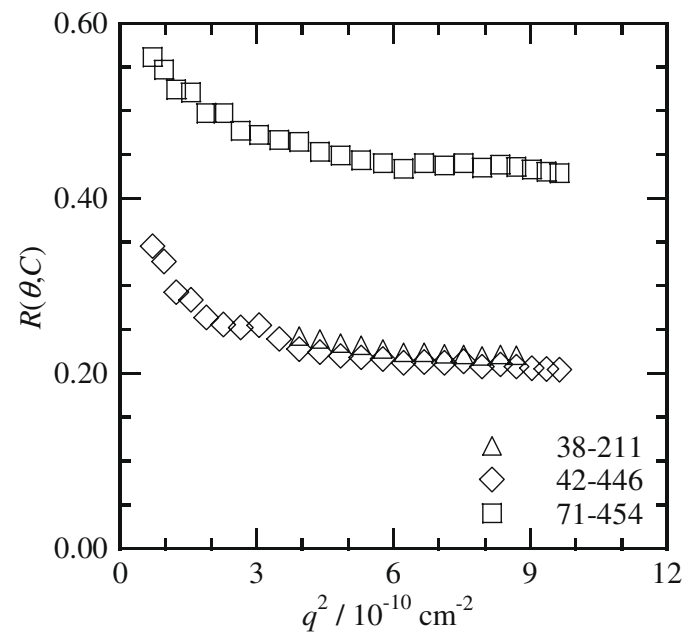

Fig. 4. Static light scattering results. $R(\theta, \mathrm{C})$ as a function of $q^{2}$ for the same mixtures as in Fig. 3.

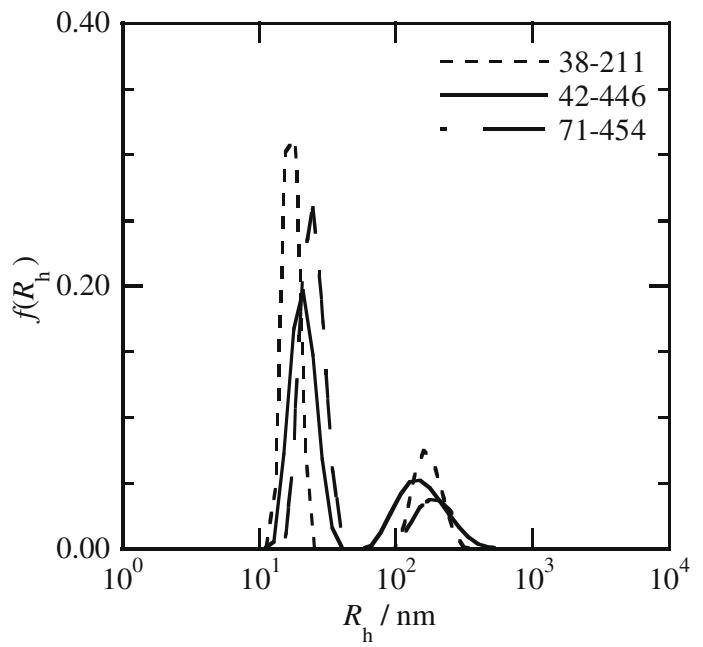

Fig. 5. CONTIN results. Equal area representation $\left(\theta=90^{\circ}\right)$ for mixtures of $\mathrm{PAA}_{305}-b-\mathrm{PVOH}_{184}$ and $\mathrm{P}_{2} \mathrm{MVP}_{38}-b-\mathrm{PEO}_{211}$ (dotted line, $C_{\mathrm{p}}=7.86 \mathrm{~g} \mathrm{l}^{-1}$, $f_{+}=0.40$ ), P2MVP $42-b-\mathrm{PEO}_{446}$ (continuous line, $C_{\mathrm{p}}=8.48 \mathrm{~g} \mathrm{l}^{-1}, f_{+}=0.39$ ), and $\mathrm{P}_{2} \mathrm{MVP}_{71}-b-\mathrm{PEO}_{454}$ (chain dotted line, $C_{\mathrm{p}}=8.01 \mathrm{~g} \mathrm{l}^{-1}, f_{+}=0.40$ ) at $1 \mathrm{mM} \mathrm{NaNO}_{3}$ and $T=21.5 \pm 0.3^{\circ} \mathrm{C}$.

used the linear dependence of $\Gamma$ on $q^{2}$ for $30^{\circ} \leqslant \theta \leqslant 145^{\circ}$ (CONTIN analysis, fast mode) and the near-linear dependence of $R(\theta, C)$ on $q^{2}$ for $70^{\circ} \leqslant \theta \leqslant 145^{\circ}$ to obtain $D^{0}$ and $R_{\mathrm{g}}{ }^{0}$ respectively. We might speculate that these aggregates originate from the rather poor solubility of PVOH $[37,38]$ or from interpolymer complexation between $\mathrm{PVOH} / \mathrm{PEO}$ and PAA chains which is known to yield insoluble complexes under more acidic conditions; that is, $\mathrm{pH}<4[39,40]$. Khutoryanskiy et al. $[39,41]$ reported on the formation of insoluble polycomplexes below $\mathrm{pH} 2.67 \pm 0.05$ for PAA and $\mathrm{PVOH}$ in salt-free solution $\left(M_{\mathrm{W}, \mathrm{PAA}}=450 \mathrm{~kg} \mathrm{~mol}^{-1}\right.$, $M_{\mathrm{w}, \mathrm{PVOH}}=205 \mathrm{~kg} \mathrm{~mol}^{-1},[\mathrm{PAA}]=[\mathrm{PVOH}]=0.01 \mathrm{M}$ in basemole units) and for $\mathrm{pH} 2.88 \pm 0.05$ for PAA and PEO in salt-free solution $\left(M_{\mathrm{w}, \mathrm{PAA}}=450 \mathrm{~kg} \mathrm{~mol}^{-1}, M_{\mathrm{w}, \mathrm{PEO}}=20 \mathrm{~kg}\right.$ $\mathrm{mol}^{-1},[\mathrm{PAA}]=[\mathrm{PEO}]=0.01 \mathrm{M}$ in base-mole units). It has also been reported that water is only a marginal solvent for $\mathrm{PVOH}$ [37], and aggregation was observed in dilute aqueous solutions of PVOH homopolymers [38]. Note, however, that the marginally soluble vinyl alcohol monomers constitute only a minor part $(\leqslant 14 \%)$ of the micellar corona.

To obtain detailed information on the micellar structure, we have obtained quantitative values for $R_{\mathrm{h}}{ }^{0}, R_{\mathrm{g}}{ }^{0}$, $R_{\mathrm{g}}{ }^{0} / R_{\mathrm{h}}{ }^{0}, M_{\mathrm{w}}$, and $P_{\mathrm{agg}}$ from the static and dynamic light scattering measurements. The results are summarised in Table 2. $R_{\mathrm{h}}{ }^{0}$ values obtained through CONTIN analysis of the data are 14.2, 17.4, and $20.4 \mathrm{~nm}$ for C3Ms of $\mathrm{PAA}_{305^{-}}$ $b-\mathrm{PVOH}_{184}$ and $\mathrm{P}_{2} \mathrm{MVP}_{38}-b-\mathrm{PEO}_{211}, \mathrm{P}_{2} \mathrm{MVP}_{42}-b-\mathrm{PEO}_{446}$, and $\mathrm{P}_{2} \mathrm{MVP}_{71}-b-\mathrm{PEO}_{454}$ respectively. They are considerably smaller than those obtained from the cumulant analysis, which is due to the fraction of aggregates. The obtained $R_{\mathrm{g}}{ }^{0} / R_{\mathrm{h}}{ }^{0}$ values agree well with those found in literature for spherical block copolymer micelles, where a $R_{\mathrm{g}}{ }^{0} / R_{\mathrm{h}}{ }^{0}$ of 0.75 (Guinier approximation)/0.78 (Zimm approximation) for C3Ms consisting of $\mathrm{PAA}_{305}-b-\mathrm{PVOH}_{184}$ and $\mathrm{P}_{2} \mathrm{MVP}_{38^{-}}$ $b-\mathrm{PEO}_{211}$ is close to the theoretical value of a hard sphere 
(0.775), while a $R_{\mathrm{g}}{ }^{0} / R_{\mathrm{h}}{ }^{0}$ of 1.34 (Guinier approximation)/ 1.43 (Zimm approximation) for C3Ms consisting of $\mathrm{PAA}_{305}-b-\mathrm{PVOH}_{184}$ and $\mathrm{P}_{2} \mathrm{MVP}_{71}-b-\mathrm{PEO}_{454}$ is close to the values reported for star-like micelles. Moreover, $M_{\mathrm{w}}$ and $P_{\text {agg }}$ show the expected trends, i.e., decrease with increasing lyophilic block length (compare $\mathrm{P}_{2} \mathrm{MVP}_{38}-b-\mathrm{PEO}_{211}$ and $\mathrm{P}_{2} \mathrm{MVP}_{42}-b-\mathrm{PEO}_{446}$ ) and increase with increasing core-forming block length (compare $\mathrm{P}_{2} \mathrm{MVP}_{42}-b-\mathrm{PEO}_{446}$ and $\left.\mathrm{P}_{2 \mathrm{MVP}} \mathrm{P}_{71}-b-\mathrm{PEO}_{454}\right) \cdot R_{\mathrm{h}}{ }^{0}$ seems to increase with overall degree of polymerisation, as observed previously [34,42], while $R_{\mathrm{g}}{ }^{0}$ shows the opposite trend. Hence, we observe an expected decrease in $R_{\mathrm{g}}{ }^{0} / R_{\mathrm{h}}{ }^{0}$ with an increase in block length of the core-forming block (compare $\mathrm{P}_{2} \mathrm{MVP}_{42}-b$ $\mathrm{PEO}_{446}$ and $\mathrm{P}_{2} \mathrm{MVP}_{71}-b-\mathrm{PEO}_{454}$ ), which may be attributed to a more compact micellar structure.

A comparison has been made between our light scattering results and a simple geometrical model for spherical micelles that has been introduced in a previous paper [10]. The results in Table 3 show that model and experiment are in rather good quantitative agreement. From the PEO cross-sections, $A_{\mathrm{PEO}}$, and the radii of gyration for the PEO polymer chains [43] in salt-free aqueous solutions, $R_{\text {g,PEO}}$, we can estimate the amount of overlap between PEO chains using $R_{\mathrm{g}, \mathrm{PEO}}{ }^{2} / A_{\mathrm{PEO}}$. For C3Ms of $\mathrm{PAA}_{305}-b-\mathrm{PVOH}_{184}$ and $\mathrm{P}_{2} \mathrm{MVP}_{38}-b-\mathrm{PEO}_{211}, \mathrm{P}_{2} \mathrm{MVP}_{42}-b-\mathrm{PEO}_{446}$ and $\mathrm{P}_{2} \mathrm{MVP}_{71^{-}}$ $b-\mathrm{PEO}_{454}$, we find values of $0.79,1.41$, and 1.32 respectively, implying that the coronal chains stabilise the micelles sufficiently as soon as they start to overlap. Note that in the above calculation, we have not taken the PVOH chains into account, which represent $<14 \%$ of the corona monomers (see below).

\subsection{Corona structure}

Recently, we have shown that in $2 \mathrm{D}{ }^{1} \mathrm{H}$ NMR NOESY experiments it is possible to observe cross-peaks between protons of two different polymer blocks in a micellar corona provided that they are in close proximity $(<0.5 \mathrm{~nm})$ [11]. On the contrary, when polymer chains were locally segregated, as was observed in C3Ms of $\mathrm{PAA}_{42}-b$-PAAm 417 and $\mathrm{P}_{2} \mathrm{MVP}_{42}-b-\mathrm{PEO}_{446}$, no cross-peaks were observed between these chains $[12,24,25]$. Similarly, 2D ${ }^{1} \mathrm{H}$ NMR NOESY experiments can provide information on the extent of chain mixing/segregation within $\mathrm{C} 3 \mathrm{Ms}$ of $\mathrm{PAA}_{305}-b$ $\mathrm{PVOH}_{184}$ and $\mathrm{P}_{2} \mathrm{MVP}_{38}-b-\mathrm{PEO}_{211}, \mathrm{P}_{2} \mathrm{MVP}_{42}-b-\mathrm{PEO}_{446}$, and
Table 4

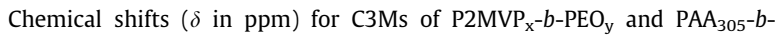
$\mathrm{PVOH}_{184}$. The numbers 1-5 correspond to protons as indicated in Fig. 1.

\begin{tabular}{lll}
\hline Proton & $\mathrm{PAA}_{305}-b-\mathrm{PVOH}_{184}$ & ${\mathrm{P} 2 \mathrm{MVP}_{\mathrm{x}}-b-\mathrm{PEO}_{\mathrm{y}}}$ \\
\hline 1 & $1.5-1.85$ & \\
2 & 2.15 & \\
3 & $1.5-1.85$ & \\
4 & $3.95-4.1$ & 3.68 \\
5 & & \\
\hline
\end{tabular}

$\mathrm{P}_{2} \mathrm{MVP}_{71}-b-\mathrm{PEO}_{454}$. The corona forming polymer blocks are rather incompatible, as was the case in the Janus-micelles containing the relatively immiscible PAAm/PEO pair. In macroscopic systems, immiscibility of PEO and PVOH chains was reported for binary blends [44,45], while Wanchoo et al. found the ternary PEO $\left(565 \mathrm{~kg} \mathrm{~mol}^{-1}\right) / \mathrm{PVOH}$ $\left(127 \mathrm{~kg} \mathrm{~mol}^{-1}\right) /$ salt-free water system to satisfy four previously posed criteria for miscibility [46]. Apart from the obvious difference in block chemistry between PVOH and PAAm, there is another important difference between the previously investigated and the current system, namely the relative size and abundance of the immiscible corona blocks and the overall shape of the micelle. While the ellipsoidal Janus-micelles contained approximately equal amounts of approximately equally sized PEO and PAAm chains, the spherical C3Ms studied here contain only $<14 \%$ PVOH blocks that are at most equally sized as compared to the PEO blocks that constitute $>86 \%$ of the micellar corona.

Fig. 6 presents contour plots of $\mathrm{C} 3 \mathrm{Ms}$ of $\mathrm{PAA}_{305}-b-$ $\mathrm{PVOH}_{184}$ and (a) $\mathrm{P}_{2} \mathrm{MVP}_{38}-b-\mathrm{PEO}_{211}$, (b) $\mathrm{P}_{2} \mathrm{MVP}_{42}-b-$ $\mathrm{PEO}_{446}$, and (c) $\mathrm{P}_{2} \mathrm{MVP}_{71}-b-\mathrm{PEO}_{454}$. The hydroxyl protons of the polyvinyl alcohol chains are not visible in the $1 \mathrm{D}$ spectrum due to proton exchange with the solvent $\left(D_{2} O\right)$. The relatively sharp peaks correspond to $13 \mathrm{C}$ satellite signals ( $\sim 3.5$ and $3.8 \mathrm{ppm}$ ) and trace amounts of solvents used during the synthesis and quaternisation procedures of $\mathrm{P}_{2} \mathrm{MVP}_{\mathrm{x}}-b-\mathrm{PEO}_{\mathrm{y}}$, as been observed previously [12]: $2.2 \mathrm{ppm}$ (acetone), 2.7, and $3.1 \mathrm{ppm}$ (presumably DMF). As observed previously [12], protons of P2MVP are not visible (arguably, as a consequence of peak broadening due to chain stiffness), so that we cannot observe cross-peaks between protons within $\mathrm{P}_{2} \mathrm{MVP}_{\mathrm{x}}-b-\mathrm{PEO}_{\mathrm{y}}$, nor within the micellar core. More importantly, we do observe large NOE's

Table 3

Comparison of model [10] with experiment for C3Ms of $\mathrm{PAA}_{305}-b-\mathrm{PVOH}_{184}$ and $\mathrm{P} 2 \mathrm{MVP}_{38}-b-\mathrm{PEO}_{211}, \mathrm{P}_{2} \mathrm{MVP}_{42}-b-\mathrm{PEO}_{446}$, and $\mathrm{P} 2 \mathrm{MVP} 71-b-\mathrm{PEO}_{454}$. Radii/nm, cross-section, $A / \mathrm{nm}^{2}$.

\begin{tabular}{|c|c|c|c|c|c|c|c|c|}
\hline \multirow{2}{*}{$\begin{array}{l}\text { System } \\
\text { Cationic polymer }\end{array}$} & \multicolumn{5}{|c|}{ Model } & \multicolumn{3}{|c|}{ Experiment } \\
\hline & $A$ & $R_{\text {total }}$ & $R_{\text {core }}$ & $n_{+}$ & $n_{-}$ & $R_{\mathrm{h}}{ }^{0}$ & $P_{\text {agg }}{ }^{+a}$ & $P_{\text {agg }}{ }^{-\mathrm{a}}$ \\
\hline $\mathrm{P}_{2 M V P} \mathrm{MV}_{38}-b-\mathrm{PEO}_{211}$ & 12.0 & 17.7 & 6.9 & 41 & 8 & 18.3 & 41 & 8 \\
\hline $\mathrm{P}_{2 M V P} \mathrm{M}_{2}-b-\mathrm{PEO}_{446}$ & 15.3 & 21.1 & 5.8 & 23 & 5 & 22.4 & 23 & 5 \\
\hline $\mathrm{P}_{2} \mathrm{MVP}_{71}-b-\mathrm{PEO}_{454}$ & 16.6 & 25.3 & 8.1 & 37 & 13 & 24.2 & 37 & 13 \\
\hline
\end{tabular}

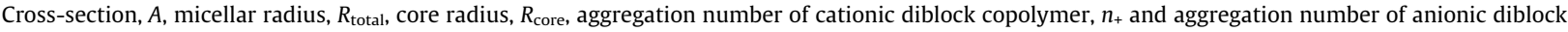
copolymer, $n_{-}$, were obtained from a simple geometrical model as described by Eqs. (2)-(6) in a previous publication [10]. Input: total volume fraction of polyelectrolyte in the micellar core, $\varphi=0.4$, density of the polyelectrolyte blocks, $\rho_{ \pm}=1.1 \mathrm{~kg} \mathrm{l}^{-1}$, density of the neutral blocks, $\rho=1.127 \mathrm{~kg} \mathrm{l}{ }^{-1}$, PAA charge density, $\alpha_{\mathrm{PAA}}=0.60, \mathrm{P} 2(\mathrm{M}) \mathrm{VP}$ charge density, $\alpha_{\mathrm{P} 2(\mathrm{M}) \mathrm{VP}}=0.91$, total volume fraction of PEO in the micellar corona, $\phi_{\mathrm{PEO} 211}=0.03, \phi_{\mathrm{PEO} 446}=\phi_{\mathrm{PEO} 454}=0.02$, total volume fraction of $\mathrm{PVOH}$ in the micellar corona, $\phi_{\mathrm{PVOH}}=\phi_{\mathrm{PEO}} . \phi_{\mathrm{PEO} 446}=\phi_{\mathrm{PEO} 454}<\phi_{\mathrm{PEO} 211}$, as the density of a polymer brush is expected to increase with decreasing block length. For a detailed explanation of the model and choice of input parameters, we refer to the publication of Hofs et al. [10].

a Obtained by the Zimm approximation. 

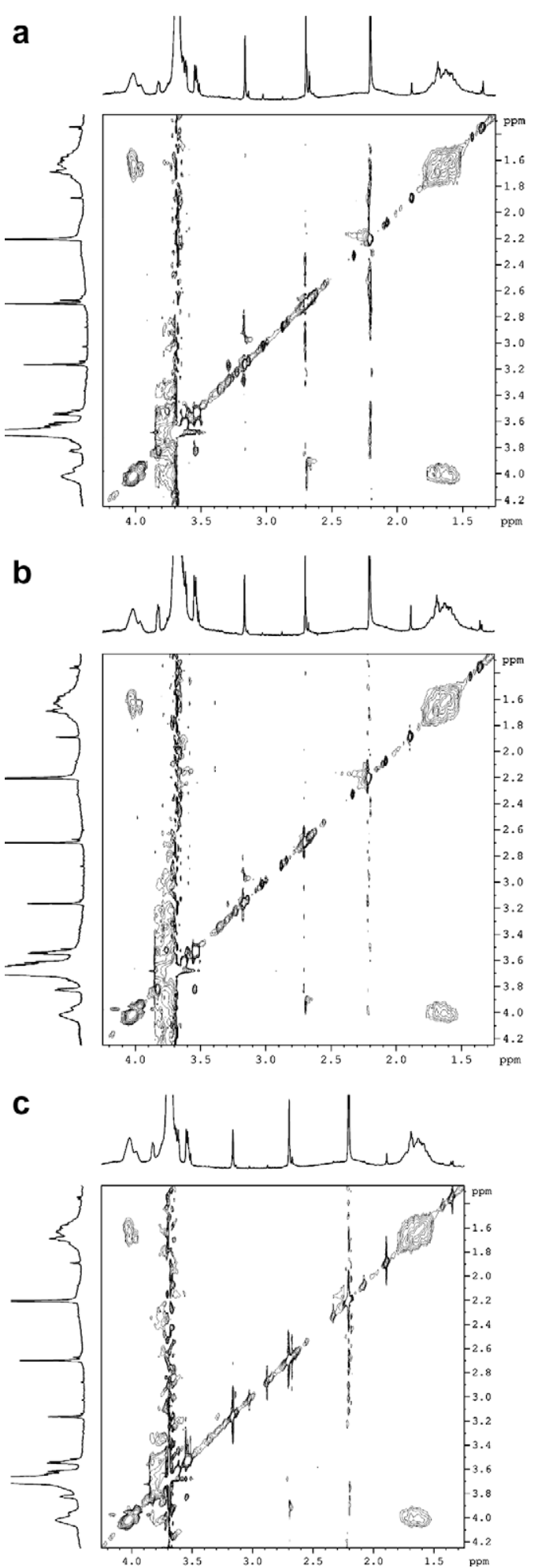

Fig. 6. $2 D{ }^{1} \mathrm{H}$ NMR NOESY contour plot of complex coacervate core micelles of (a) $\mathrm{PAA}_{305}-b-\mathrm{PVOH}_{184}$ and $\mathrm{P}_{2} \mathrm{MVP}_{38}-b-\mathrm{PEO}_{211}$, (b) $\mathrm{P}_{2} \mathrm{MVP}_{42}-b-$ $\mathrm{PEO}_{446}$, and (c) $\mathrm{P}_{2} \mathrm{MVP}_{71}-b-\mathrm{PEO}_{454}$ for the same mixtures as in Fig. 3. Peaks have been assigned (Table 4) on the basis of the 1D spectra. Crosscorrelations between PEO (proton 5) and PVOH blocks (protons 3, 4) were not observed, while there are large NOE's within $\mathrm{PAA}_{305}-b-\mathrm{PVOH}_{184}$ (proton 4 and 1 and/or 3; proton 1 and 3). between neighbouring protons within $\mathrm{PAA}_{305}-b-\mathrm{PVOH}_{184}$, but no cross-correlations between protons of $\mathrm{PVOH}$ and $\mathrm{PEO}$, i.e., indicative of segregation of $\mathrm{PEO}$ and $\mathrm{PVOH}$ chains in the micellar corona.

Hence, whereas previously we observed chain mixing in spherical micelles and chain segregation in ellipsoidal micelles, we now have indications for local segregation within the corona of spherical micelles. Naturally, one starts to wonder whether this is related to a difference in the type of local segregation that occurs in the micellar corona of ellipsoidal PAAm/PEO and spherical PVOH/PEO micelles. Indeed, if we take into account that the corona constitutes of $\leqslant 14 \%$ vinyl alcohol monomers, and the fact that water is only a marginal solvent for $\mathrm{PVOH}$ and a good solvent for PEO at $T=25^{\circ} \mathrm{C}$, we might argue that a Janus-type segregation into two equally sized laterally segregated domains is rather unlikely, whereas a combined radial and lateral segregation into a certain number and size of patches - as schematically depicted in Fig. 7 - seems much more likely. Such 'patchy micelles' (also known as 'raspberry-like' micelles, micelles with a 'spheres-on-sphere' morphology, or 'multicompartment (core) micelles') have been achieved lately in a number of micellar systems consisting of self-assembled terpolymers and $\mathrm{H}$-bonded diblock and triblock copolymers, that were typically asymmetric; that is, with a large asymmetry in size and/ or abundance between the two incompatible core-forming blocks (see for example Refs. [47-50]) or corona-forming blocks (see for example Refs. [51-53]). Finally, we would like to point out that self-consistent field calculations on bimodal (bidisperse) brushes (polymer brushes consisting of two types of polymers differing only in size; that is, identical in chemical composition) have demonstrated that patchy brushes can arise merely as a result of a distinct difference in polymer block length [54]; that is, without any chemical incompatibility as all polymer chains were of identical chemical composition.

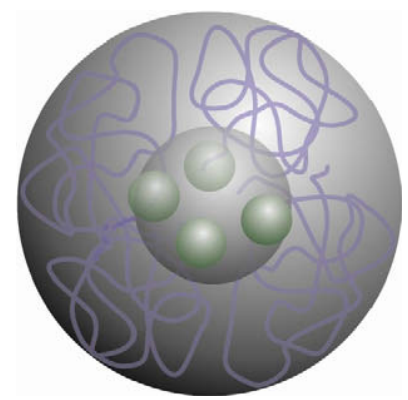

Fig. 7. Schematic representation of $C 3 \mathrm{Ms}$ of $\mathrm{P}^{2} \mathrm{MVP}_{\mathrm{x}}-b-\mathrm{PEO}_{\mathrm{y}}$ and $\mathrm{PAA}_{305}$ $b-\mathrm{PVOH}_{184}$ at $1 \mathrm{mM} \mathrm{NaNO}_{3}$ and $25^{\circ} \mathrm{C}\left(x_{1}=38, y_{1}=211, x_{2}=42, y_{2}=446\right.$, $\left.x_{3}=71, y_{3}=454\right)$. The C3Ms consist of a mixed PAA/P2MVP complex coacervate core, surrounded by a two-layered shell. The PVOH chains form 'patches' on the core, i.e., they are less swollen, and less stretched, than the PEO chains, as water is a marginal solvent for the vinyl alcohol segments and a good solvent for the PEO segments. Hence, the C3Ms could be described as a 'patched' micelle. 


\subsection{Self-consistent field calculations}

To investigate whether a difference in chemical composition between two polymers within the same brush can likewise give rise to a patchy brush structure, we turned to self-consistent field (SCF) modeling. In particular, we investigated brushes of strongly asymmetric composition as is the case in the current experimental system - and varied the relative length of the polymer blocks, the polymer-solvent interaction parameter (related to the solvent quality of one of the polymers), and the polymer-polymer interaction parameter (related to the miscibility between the polymers) to study their effect on the brush structure. Preliminary results are described in the following. We refer to previous work, for example Ref. [55] for a detailed explanation of the theory, SCF machinery, and for SCF calculations on polymer brushes. We assume that the choice of geometry will not significantly influence the results and thus opt for a flat geometry to maximise the computational speed, whereas in reality of course, the $\mathrm{PEO} / \mathrm{PVOH}$ brush is of spherical geometry. Hence, in the calculations the system consists of two polymers A and $\mathrm{B}$, representing PVOH and PEO. The chains are grafted to an impenetrable surface. Two types of calculations were performed. First, only gradients in the volume fraction profiles normal to the surface were considered (one-gradient (1G) calculations, i.e., in the $z$-direction and mean field approximation in the $x-y$ plane). Here the chains can not diffuse laterally


Fig. 8. Results of SCF calculations for a flat brush composed of PVOH and PEO polymers. (a, b) Brush height, $h_{\mathrm{g}}$ (in units of lattice sites) of PVOH (lines) and PEO (dashed) as a function of the PVOH-water Flory Huggins interaction parameter, $\chi_{\text {PVOH-w }}$, for $0 \leqslant \chi_{\text {PEO-PVOH }} \leqslant 0.4$ as indicated, for $(a) N_{\text {PEO }}=200(1 G)$, (b) $N_{\text {PEO }}=400$ (1G). (c, d) Two-gradient volume fraction, $\phi(x, z)$ profiles for (c, e) PVOH and (d, f) PEO, for (c, d) $N_{\text {PEO }}=400$ and (e, f) $N_{\text {PEO }}=200$. $\chi_{\text {PEO- }}$ ${ }_{\mathrm{PVOH}}=0.4$ and $\chi_{\mathrm{PVOH}-\mathrm{W}}=0.52$. Input parameters: $\chi_{\mathrm{PEO}-\mathrm{W}}=0.4, N_{\mathrm{PVOH}}=300$. In the $2 \mathrm{G}$ calculations, the chains have lateral mobility in the $x$-direction. A cubic lattice is used with reflecting boundary conditions in the $x$-direction. The grafting surface is positioned at $z=0$. The lateral inhomogeneity of the brush follows from the fact that the profiles vary in the $x$-direction. We have chosen to place the collapsed chain (PVOH) to be around $x=30$. In all cases the brush consists of $90 \%$ vinyl alcohol monomers and $10 \%$ ethylene oxide monomers and the total amount of polymer equals 3.3 equivalent monolayers. 
and can only segregate in the normal direction. Second, two gradients, one perpendicular and one parallel to the surface, were considered ( $2 \mathrm{G}$ calculations, i.e., both in the $x$ - and $z$-direction and the mean-field approximation in the $y$-direction). In the latter case the chains can translate along the surface and the system can segregate both in the normal as well as in the parallel direction with respect to the surface. The amount of ethylene oxide monomers is fixed to $90 \%$ and the amount of vinyl alcohol monomers to $10 \%$. The PEO-water Flory Huggins interaction parameter, $\chi_{\text {PEO-W, }}$, is fixed at 0.4 (i.e., good solvent conditions), while both $\chi_{\mathrm{PVOH}} \mathrm{w}$ and $\chi_{\mathrm{PEO}-\mathrm{PVOH}}$ are varied. Moreover, calculations were performed for systems with both longer $\left(N_{\mathrm{PEO}}=400\right)$ and shorter PEO $\left(N_{\mathrm{PEO}}=200\right)$ than $\mathrm{PVOH}$ chains $\left(N_{\mathrm{PVOH}}=300\right)$. Results are given in Fig. 8. In panels $a$ and $b$ the $1 G$ results are given. Here the first moment over the end-point distribution of both the PEO as well as the PVOH polymers, $h_{\mathrm{g}}$, is plotted versus $\chi_{\mathrm{PVOH}-\mathrm{W} \text {. In }}$ panels c-f the volume fraction profiles $\varphi(x, z)$ for PEO and PVOH are shown for a special case: $\chi_{\mathrm{PEO}-\mathrm{PVOH}}=0.4$ and $\chi_{\mathrm{PVOH}-\mathrm{W}}=0.52$ potentially resembling the experimental situation, as described above, where the solvent quality of $\mathrm{PVOH}$ is marginal, that of PEO is slightly better, and PEO and PVOH are rather incompatible $[37,44,45]$. Note that we purposely neglected potential disparities in surface affinity et cetera, as they are, to the best of our knowledge, not known for the system.

It is clear from the $1 \mathrm{G}$ calculations in Fig. $8 \mathrm{a}$ and $\mathrm{b}$ that the PEO and PVOH are segregated in the $z$-direction, thus avoiding each other, under nearly all conditions. In part this is due to the difference in solvent quality, the difference in the length of the chains, and differences in grafting density (the majority component is closest to the surface), moreover, the miscibility of PEO and PVOH segments is naturally of importance. Strikingly, the PVOH chains nearly always reside on the outside of the brush $h_{\mathrm{g}, \mathrm{PEO}}<h_{\mathrm{g}, \mathrm{PVOH}}$ (even if they are shorter than the PEO chains), except for very poor solvent quality for $\mathrm{PVOH}\left(\chi_{\mathrm{PVOH}-\mathrm{W}}>0.5\right)$ where they collapse onto the surface. The $\chi_{\mathrm{PVOH}-\mathrm{w}}$ where the transition occurs is shifted to lower values for longer PEO chains, and less repulsion between PEO and PVOH segments (i.e., smaller values of $\left.\chi_{\mathrm{PEO}-\mathrm{PVOH}}\right)$. For $N_{\mathrm{PEO}}=400$ and $\chi_{\mathrm{PEO}-\mathrm{PVOH}}=0.4$ (Fig. $8 \mathrm{~b}$ ), we observe a hysteresis in the volume fraction profiles proving the segregation transition is a jump-like (first-order) transition. In such case the natural question arises whether the transition is influenced by lateral mobility. Hence, $2 \mathrm{G}$ calculations were performed (Fig. 8c-f). As expected, we observe both lateral and radial segregation of PEO and PVOH chains for $\chi_{\mathrm{PEO}-\mathrm{PVOH}}=0.4$ and $\chi_{\mathrm{PVOH}-\mathrm{W}}=0.52$ for $N_{\mathrm{PEO}}=400$. The swollen PEO chains surround and enclose these collapsed chains. Interestingly for $N_{\text {PEO }}=200$, where in the $1 \mathrm{G}$ calculations one homogeneous solution was found, we also observe a lateral inhomogeneous layer.

The difference between $1 G$ and $2 \mathrm{G}$ results for a mixed polymer brush definitely needs further investigation. To our opinion, these preliminary SCF results (even though we did not yet focus on the correct geometry and neglected several other complications) support the conclusion that the C3Ms of PAA- $b$-PVOH and PMVP- $b$-PEO are likely to resemble a 'patched micelle' as depicted in Fig. 7. Whether the patches that are surrounded by relatively swollen polymer blocks, consist of PVOH or PEO segments depends on PVOH solvent quality, the PEO/PVOH block length ratio, and the extent of PEO/PVOH incompatibility.

\section{Conclusions}

Using light scattering measurements, we have followed the formation of micelles of poly $(N$-methyl-2-vinyl pyridinium iodide)-block-poly(ethylene oxide), $\mathrm{P}_{2} \mathrm{MVP}_{38}-b-$ $\mathrm{PEO}_{211}$ and poly(acrylic acid)-block-poly(vinyl alcohol), $\mathrm{PAA}_{305}-b-\mathrm{PVOH}_{184}$ in aqueous solutions. At the preferred micellar composition, $f_{+}=0.40$, spherical micelles are formed of relatively low polydispersity (PDI $<0.2$ ) with $R_{\mathrm{h}, 90^{\circ}}=18.1 \pm 0.3 \mathrm{~nm} \quad\left(C_{\mathrm{p}}=1.87 \mathrm{~g} \mathrm{l}^{-1}, \quad 1 \mathrm{mM} \quad \mathrm{NaNO}_{3}\right.$, $\left.T=25.0 \pm 0.1^{\circ} \mathrm{C}\right)$. DLS and SLS experiments on aqueous solutions of $\mathrm{PAA}_{305}-b-\mathrm{PVOH}_{184}$ and $\mathrm{P}_{2} \mathrm{MVP}_{38}-b-\mathrm{PEO}_{211}$, $\mathrm{P}_{2 M V P} \mathrm{M}_{2}-b-\mathrm{PEO}_{446}$, or $\mathrm{P}_{2 \mathrm{MVP}}-b-\mathrm{PEO}_{454}$ show a coexistence of these micelles with larger aggregates. The experimental results were compared to a simple geometrical model, yielding cross-sections from $12-17 \mathrm{~nm}^{2}$ and coronal volume fractions $\leqslant 0.03$, implying that colloidal stabilisation can be achieved when coronal chains start to overlap. From a careful consideration of the experimental observations in combination with our self-consistent field (SCF) calculations, we infer that the relatively immiscible PEO/ PVOH pair does not yield ellipsoidal Janus-micelles, but rather spherical patchy micelles as schematically depicted in Fig. 7. Whether the patches correspond to PVOH or PEO (and conversely, the swollen chains to PEO or PVOH) depends on the PVOH-water and PVOH-PEO interaction parameters (in other words, the PVOH solvent quality and the PVOH/PEO miscibility) and the PEO/PVOH block length ratio. Finally, we would like to remark that these dependencies might be investigated quantitatively in for example Cryo-TEM experiments on a system where one of the coronal blocks could be stained selectively, which is not the case in the present system. Moreover, we suppose that a more symmetric PEO/PVOH system would consist of ellipsoidal Janus-micelles, as was found for the rather symmetric

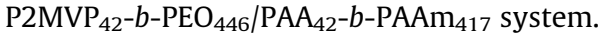

\section{Acknowledgments}

This work is part of the research programme of the Stichting voor Fundamenteel Onderzoek der Materie (FOM), which is financially supported by the Nederlandse Organisatie voor Wetenschappelijk Onderzoek (NWO). It has been carried out in the framework of the EU Polyamphi/Marie Curie program (FP6-2002, proposal 505027). One of us was financed by the SONS Eurocores program (Project JA016-SONS-AMPHI). The authors gratefully thank Remco Fokkink and Peter Barneveld for their technical support with the light scattering measurements and software respectively (AfterALV, www.dullware.nl). Holger Schmalz is gratefully acknowledged for the synthesis of the P2MVP$b$-PEO polymers. A.D., C.D. and R.J. are grateful to the 'Belgian Science Policy' for general support in the frame of the 'Interuniversity Attraction Poles Programme (PAI VI/27) Functional Supramolecular Systems', to the Fonds National de la Recherche Scientifique (F.N.R.S., Belgium) and to 
Christophe Hubens and Raphaël Essers for their skillful assistance. A.D. and C.D. are 'Chargé de Recherche' and 'Chercheur Qualifié' by the 'Fonds National de la Recherche Scientifique' (FNRS, Brussels), respectively.

\section{Appendix A}

\section{A.1. Light scattering-titrations (LS-T)}

$i_{\text {rel }}^{\sigma}$ is defined in Eqs. (3)-(5) as the Rayleigh ratio of the sample minus the reduced Rayleigh ratios of the 'blanks' (the polymer solutions in the burette and scattering cell), all divided by the total polymer concentration at $f_{+}=0.5, c^{*}$.

$$
\begin{aligned}
i_{\text {rel }}^{\sigma} & =\frac{I_{\text {sample }}-I_{\text {solvent }}-i_{c t}-i_{b t}}{c^{*} \times I_{\text {toluene }}}=\frac{I_{\text {sample }}-I_{\text {solvent }}-i_{c t}-i_{b t}}{\left(c_{b . f_{+}=0.5}+c_{c, f+=0.5}\right) \times I_{\text {toluene }}} \\
& =\frac{I_{\text {sample }}-I_{\text {solvent }}-i_{c t}-i_{b t}}{c_{c, f_{+}=0.5}\left(1+\frac{q_{c}}{q_{b}} \cdot \frac{M_{b}}{M_{c}}\right) \times I_{\text {toluene }}} \\
i_{c t} & =\left(I_{c 0}-I_{\text {solvent }}\right) \times \frac{c_{c t}}{c_{c 0}} \\
i_{b t} & =\left(I_{b 0}-I_{\text {solvent }}\right) \times \frac{c_{b t}}{c_{b 0}}
\end{aligned}
$$

The subscripts ' $b$ ' and ' $c$ ' denote the polymer in the burette and scattering cell respectively, prior to the LS-T. The subscripts ' 0 ', ' $f_{+}=0.5$ ' and ' $t$ ' denote before LS-T, during LS-T at $f_{+}=0.5$ and during LS-T at $f_{+}$corresponding to a certain value ' $t$ ', respectively. $q_{b}$ and $q_{c}$ are the number of chargeable groups in polymer $b$ and polymer $c$, while $M_{b}$ and $M_{c}$ are their molar masses.

In this manner, the 'blanks' are subtracted according to what they would contribute to the scattering at the actual $f_{+}$if no complexation would occur, $i_{c t}$ and $i_{b t}$, i.e., only excess scattering due to complexation remains. Furthermore, division by the total polymer concentration is necessary to be able to compare measurements independent of the initial concentration of the stock solutions. For C3M systems, it seems most logical to divide by $c^{*}$, the total polymer concentration corresponding to the preferred micellar composition, PMC[34] in the ideal case, i.e., when the charge neutrality condition is met at $f_{+}=0.5$ (equal amounts of chargeable groups). Whether the PMC occurs at $f_{+}=0.5$, depends on the $\mathrm{pH}$ of the polymer stock solutions in case one or both of the polymers contain(s) weak polyelectrolyte groups.

\section{Appendix B}

\section{B.1. Static light scattering (SLS)}

The excess Rayleigh ratio, $R(\theta, C)$, is given by

$$
R(\theta, C)=\frac{I_{\text {sample }}-I_{\text {solvent }}}{I_{\text {reference }}}\left(\frac{n^{2}}{n_{\text {reference }}^{2}}\right) R(\theta)_{\text {reference }}
$$

In the Zimm approximation, for sufficiently dilute conditions, $R(\theta, C)$ is given by

$$
\begin{aligned}
& \frac{K C}{R(\theta, C)} \approx \frac{1}{M_{\mathrm{w}}}\left(1+\frac{1}{3} R_{\mathrm{g}}^{2} q^{2}\right), \text { and } \\
& K=\frac{4 \pi^{2} n^{2}}{N_{\mathrm{av}} \lambda_{0}^{4}}\left(\frac{d n}{d c}\right)^{2},
\end{aligned}
$$

where $K$ is an optical constant, $N_{\mathrm{av}}$ is Avogadro's number, $\lambda_{0}$ is the wavelength of the laser $(514.5 \mathrm{~nm}), \mathrm{n}$ is the solvent refractive index $\left(1.332\right.$ for $\mathrm{H}_{2} \mathrm{O}, T=25.0 \pm 0.1^{\circ} \mathrm{C}$; 1.331 for $\left.\mathrm{D}_{2} \mathrm{O}, T=21.5 \pm 0.3^{\circ} \mathrm{C}\right), d n / d c$ the specific refractive index increment, and $q$ the magnitude of the scattering wave vector, given by

$q=\frac{4 \pi n}{\lambda_{0}} \sin \left(\frac{\theta}{2}\right)$

Alternatively, in the Guinier approximation for sufficiently dilute conditions, $K C / R(\theta, C)$ is given by

$\frac{K C}{R(\theta, C)} \approx \frac{1}{M_{\mathrm{w}}} \exp \left(\frac{1}{3} q^{2} R_{\mathrm{g}}^{2}\right)$

Thus, from the intercept and slope in the extrapolation of $K C / R(\theta, C)$ to zero angle at a given concentration, one obtains the apparent molecular weight, $M_{\mathrm{w}}$ of the scattering particle and its apparent radius of gyration, $R_{\mathrm{g}}{ }^{0}$.

\section{Appendix C}

Consider a strict core-shell segregation where all PAA/ PVOH and P2MVP/PEO junctions are locked to the core/ corona interface, restricting the number of possible chain conformations. It is likely that the short cationic blocks are incapable of compensating all charges of the much longer anionic blocks, i.e., it would involve a considerable stretching penalty if at all possible, so that small, monovalent counterions are taken up by the micellar core to establish charge neutrality. To test this latter proposition, one should determine the PMC for C3Ms of P2MVP- $b$-PEO and PAA- $b$-PVOH of which the PAA/P2MVP block length ratio is systematically varied. Finally, we note that a considerable difference in solubility between the cationic and the anionic polymer, could also give rise to a displacement of the PMC from $f_{+}=0.5$. However, if we follow this line of reasoning, we should regard the minority component, here the cationic copolymer, as the more soluble component, which is in contradiction with the presence of residual excess scattering at large values of $f_{+}$as discussed in the main body of the text.

\section{References}

[1] Cohen Stuart MA, Hofs B, Voets IK, de Keizer A. Assembly of polyelectrolyte-containing block copolymers in aqueous media. Curr Opin Colloid Interface Sci 2005;10(1-2):30-6.

[2] Harada A, Kataoka K. Effect of charged segment length on physicochemical properties of core-shell type polyion complex micelles from block ionomers. Macromolecules 2003;36(13): 4995-5001.

[3] Stapert HR, Nishiyama N, Jiang DL, Aida T, Kataoka K. Polyion complex micelles encapsulating light-harvesting ionic dendrimer zinc porphyrins. Langmuir 2000;16(21):8182-8.

[4] Chen W, Chen HR, Hu JH, Yang WL, Wang CC. Synthesis and characterization of polyion complex micelles between poly(ethylene glycol)-grafted poly(aspartic acid) and cetyltrimethyl ammonium bromide. Colloids Surf A Physicochem Eng Aspects 2006;278(13):60-6.

[5] Harada A, Kataoka K. On-off control of enzymatic activity synchronizing with reversible formation of supramolecular assembly from enzyme and charged block copolymers. J Am Chem Soc 1999;121(39):9241-2.

[6] Solomatin SV, Bronich TK, Bargar TW, Eisenberg A, Kabanov VA, Kabanov AV. Environmentally responsive nanoparticles from block 
ionomer complexes: effects of $\mathrm{pH}$ and ionic strength. Langmuir 2003;19(19):8069-76.

[7] Lysenko EA, Chelushkin PS, Bronich TK, Eisenberg A, Kabanov VA Kabanov AV. Formation of multilayer polyelectrolyte complexes by using block ionomer micelles as nucleating particles. J Phys Chem B 2004;108(33):12352-9.

[8] Gohy JF, Varshney SK, Antoun S, Jerome R. Water-soluble complexes formed by sodium poly(4-styrenesulfonate) and a poly(2-vinylpyridinium)-block-poly(ethyleneoxide) copolymer. Macromolecules 2000;33(25):9298-305.

[9] van der Burgh S, Fokkink R, de Keizer A, Cohen Stuart MA. Complex coacervation core micelles as anti-fouling agents on silica and polystyrene surfaces. Colloids Surf A Physicochem Eng Aspects 2004;242(1-3):167-74

[10] Hofs B, Voets IK, de Keizer A, Cohen Stuart MA. Comparison of complex coacervate core micelles from two diblock copolymers or a single diblock copolymer with a polyelectrolyte. Phys Chem Chem Phys 2006;8(36):4242-51.

[11] Voets IK, de Keizer A, Cohen Stuart MA, de Waard P. Core and corona structure of mixed polymeric micelles. Macromolecules 2006;39(17): 5952-5.

[12] Voets IK, de Keizer A, de Waard P, Frederik PM, Bomans PHH, Schmalz $H$, et al. Double-faced micelles from water-soluble polymers. Angew Chem Int Ed 2006;45(40):6673-6.

[13] Voets IK, de Keizer A, Cohen Stuart MA. Complex coacervate core micelles. Adv Colloid Interface Sci 2009;147-48:300-18.

[14] Nisha CK, Manorama SV, Kizhakkedathu JN, Maiti S. Water-soluble complexes from random copolymer and oppositely charged surfactant. 2. Complexes of poly(ethylene glycol)-based cationic random copolymer and bile salts. Langmuir 2004;20(20):8468-75.

[15] Bronich TK, Nguyen HK, Eisenberg A, Kabanov AV. Recognition of DNA topology in reactions between plasmid DNA and cationic copolymers. J Am Chem Soc 2000;122(35):8339-43.

[16] Wakebayashi D, Nishiyama N, Yamasaki Y, Itaka K, Kanayama N, Harada A, et al. Lactose-conjugated polyion complex micelles incorporating plasmid DNA as a targetable gene vector system: their preparation and gene transfecting efficiency against cultured HepG2 cells. J Control Release 2004;95(3):653-64.

[17] Oishi M, Nagasaki Y, Itaka K, Nishiyama N, Kataoka K. Lactosylated poly(ethylene glycol)-siRNA conjugate through acid-labile ssthiopropionate linkage to construct $\mathrm{pH}$-sensitive polyion complex micelles achieving enhanced gene silencing in hepatoma cells. J Am Chem Soc 2005;127(6):1624-5.

[18] Wu K, Shi LQ, Zhang WQ, An YL, Zhu XX, Zhang X, et al. Formation of hybrid micelles between poly(ethylene glycol)-block-poly(4vinylpyridinium) cations and sulfate anions in an aqueous milieu. Soft Matter 2005;1(6):455-9.

[19] Wu K, Shi LQ, Zhang WQ, An YL, Zhang X, Li ZY, et al. Thermoresponsiveness of hybrid micelles from poly(ethylene glycol)-blockpoly(4-vinylpyridium) cations annul $\mathrm{SO}_{4}{ }^{2-}$ anions in aqueous solutions. Langmuir 2006;22(4):1474-7.

[20] Yan Y, Besseling NAM, de Keizer A, Marcelis ATM, Drechsler M Cohen Stuart MA. Hierarchical self-assembly in solutions containing metal ions, ligand, and diblock copolymer. Angew Chem Int Ed 2007;46(11):1807-9.

[21] Harada A, Kataoka K. Supramolecular assemblies of block copolymers in aqueous media as nanocontainers relevant to biological applications. Prog Polym Sci 2006;31(11):949-82.

[22] Kataoka K, Harada A, Nagasaki Y. Block copolymer micelles for drug delivery: design, characterization and biological significance. Adv Drug Deliv Rev 2001;47(1):113-31.

[23] Kabanov AV, Kabanov VA. Interpolyelectrolyte and block ionomer complexes for gene delivery: physicochemical aspects. Adv Drug Deliv Rev 1998;30(1-3):49-60.

[24] Voets IK, Fokkink R, de Keizer A, May RP, de Waard P, Cohen Stuart MA. On the transition between a heterogeneous and homogeneous corona in mixed polymeric micelles. Langmuir 2008;24(21): 12221-7.

[25] Voets IK, Fokkink R, Hellweg T, King SM, de Waard P, de Keizer A et al. Spontaneous symmetry breaking: formation of Janus micelles. Soft Matter 2009;5(5):999-1005.

[26] Voets IK, Moll PM, Aqil A, Jerome C, Detrembleur C, de Waard P, et al. Temperature responsive complex coacervate core micelles with a PEO and PNIPAAm corona. J Phys Chem B 2008;112(35):10833-40.

[27] Schmalz H, Lanzendorfer MG, Abetz V, Müller AHE. Anionic polymerization of ethylene oxide in the presence of the phosphazene base (BuP4)-P-t - Kinetic investigations using in-situ FT-NIR spectroscopy and MALDI-ToF MS. Macromol Chem Phys 2003;204(8):1056-71.
[28] Debuigne A, Warnant J, Jerome R, Voets I, de Keizer A, Cohen Stuart MA, et al. Synthesis of novel well-defined poly(vinyl acetate)-bpoly(acrylonitrile) and derivatized water-soluble poly(viny alcohol)-b-poly(acrylic acid) block copolymers by cobalt-mediated radical polymerization. Macromolecules 2008;41(7):2353-60.

[29] Debuigne A, Caille JR, Detrembleur C, Jerome R. Effective cobalt mediation of the radical polymerization of vinyl acetate in suspension. Angew Chem Int Ed 2005;44(22):3439-42.

[30] Debuigne A, Caille JR, Jerome R. Highly efficient cobalt-mediated radical polymerization of vinyl acetate. Angew Chem Int Ed 2005;44(7):1101-4

[31] Salomaa P, Schaleger LL, Long FA. Solvent deuterium isotope effects on acid-base equilibria. J Am Chem Soc 1964;86(1):1-7.

[32] Lindhoud S, Norde W, Cohen Stuart MA. Reversibility and relaxation behavior of polyelectrolyte complex micelle formation. J Phys Chem B 2009;113(16):5431-9.

[33] Hofs B, de Keizer A, Cohen Stuart MA. On the stability of (highly aggregated) polyelectrolyte complexes containing a chargedblock-neutral diblock copolymer. J Phys Chem B 2007;111(20): 5621-7.

[34] van der Burgh S, de Keizer A, Cohen Stuart MA. Complex coacervation core micelles. Colloidal stability and aggregation mechanism. Langmuir 2004;20(4):1073-84.

[35] van der Burgh S. Complex coacervate core micelles in solution and at interfaces. Wageningen: Wageningen Universiteit; 2004. p. 128.

[36] Voets IK, de Keizer A, Cohen Stuart MA, Justynska J, Schlaad H. Irreversible structural transitions in mixed micelles of oppositely charged diblock copolymers in aqueous solution. Macromolecules 2007;40(6):2158-64.

[37] Hong PD, Chou CM, He CH. Solvent effects on aggregation behavior of polyvinyl alcohol solutions. Polymer 2001;42(14):6105-12.

[38] Tacx J, Schoffeleers HM, Brands AGM, Teuwen L. Dissolution behavior and solution properties of polyvinylalcohol as determined by viscometry and light scattering in DMSO, ethyleneglycol and water. Polymer 2000;41(3):947-57.

[39] Khutoryanskiy VV, Dubolazov AV, Nurkeeva ZS, Mun GA. pH effects in the complex formation and blending of poly(acrylic acid) with poly(ethylene oxide). Langmuir 2004;20(9):3785-90.

[40] Nurkeeva ZS, Mun GA, Dubolazov AV, Khutoryanskiy VV. PH effects on the complexation, miscibility and radiation-induced crosslinking in poly(acrylic acid)-poly (vinyl alcohol) blends. Macromol Biosci 2005;5(5):424-32.

[41] Khutoryanskiy VV, Mun GA, Nurkeeva ZS, Dubolazov AV. pH and salt effects on interpolymer complexation via hydrogen bonding in aqueous solutions. Polym Int 2004;53(9):1382-7.

[42] Voets IK, van der Burgh S, Farago B, Fokkink R, Kovacevic D, Hellweg $\mathrm{T}$, et al. Electrostatically driven coassembly of a diblock copolyme and an oppositely charged homopolymer in aqueous solutions Macromolecules 2007;40(23):8476-82.

[43] Kawaguchi S, Imai G, Suzuki J, Miyahara A, Kitano T. Aqueous solution properties of oligo- and poly(ethylene oxide) by static light scattering and intrinsic viscosity. Polymer 1997;38(12):2885-91.

[44] Lai WC, Liau WB. Study of the miscibility and crystallization behavior of poly(ethylene oxide)/poly(vinyl alcohol) blends. J Appl Polym Sci 2004;92(3):1562-8.

[45] Vijayalakshmi SP, Madras G. Thermal degradation of water soluble polymers and their binary blends. J Appl Polym Sci 2006;101(1): 233-40.

[46] Wanchoo RK, Narula M, Thakur A. Miscibility studies on some water soluble polymer-polymer blends. J Polym Mater 2007;24(1):57-64

[47] Schacher F, Walther A, Ruppel M, Drechsler M, Mueller AHE. Multicompartment core micelles of triblock terpolymers in organic media. Macromolecules 2009;42(10):3540-8.

[48] Uchman M, Stepanek M, Prochazka K, Mountrichas G, Pispas S, Voets IK, et al. Multicompartment nanoparticles formed by a heparinmimicking block terpolymer in aqueous solutions. Macromolecules, in press, doi: $10.1021 / \mathrm{ma} 9008115$.

[49] Kubowicz S, Baussard JF, Lutz JF, Thunemann AF, von Berlepsch H, Laschewsky A. Multicompartment micelles formed by self-assembly of linear ABC triblock copolymers in aqueous medium. Angew Chem Int Ed 2005;44(33):5262-5.

[50] Ritzenthaler S, Court F, David L, Girard-Reydet E, Leibler L, Pascault JP. ABC triblock copolymers/epoxy-diamine blends. 1. Keys to achieve nanostructured thermosets. Macromolecules 2002;35(16): 6245-54.

[51] Hoppenbrouwers E, Li Z, Liu GJ. Triblock nanospheres with amphiphilic coronal chains. Macromolecules 2003;36(3):876-81.

[52] Kuo SW, Tung PH, Lai CL, Jeong KU, Chang FC. Supramolecular micellization of diblock copolymer mixtures mediated by hydrogen 
bonding for the observation of separated coil and chain aggregation in common solvents. Macromol Rapid Commun 2008;29(3): $229-33$.

[53] Gohy JF, Khousakoun E, Willet N, Varshney SK, Jerome R. Segregation of coronal chains in micelles formed by supramolecular interactions. Macromol Rapid Commun 2004;25(17):1536-9.
[54] Dan N, Tirrell M. Effect of bimodal molecular-weight distribution on the polymer brush. Macromolecules 1993;26(24):6467-73.

[55] Fleer GJ, Cohen Stuart MA, Scheutjens JMHM, Cosgrove T, Vincent B. Polymers at interfaces. London: Chapman \& Hall; 1993.

[56] Hardy RC, Cottington RL. Viscosity of deuterium oxide and water in the range $5{ }^{\circ} \mathrm{C}$ to $125^{\circ} \mathrm{C}$. J Res Natl Bur Stand 1949;42(6):573-8. 